\title{
Study of prone positioning to reduce ventilator-associated pneumonia in hypoxaemic patients
}

\author{
R. Mounier, C. Adrie, A. Français, M. Garrouste-Orgeas, C. Cheval, B. Allaouchiche, \\ S. Jamali, A.T. Dinh-Xuan, D. Goldgran-Toledano, Y. Cohen, E. Azoulay, J-F.Timsit \\ and J-D. Ricard, on behalf of the OUTCOMEREA Study Group
}

ABSTRACT: The aim of the present study was to examine whether prone positioning (PP) affects ventilator associated-pneumonia (VAP) and mortality in patients with acute lung injury/adult respiratory distress syndrome.

2,409 prospectively included patients were admitted over 9 yrs (2000-2008) to 12 French intensive care units (ICUs) (OUTCOMEREA). The patients required invasive mechanical ventilation (MV) and had arterial oxygen tension/inspiratory oxygen fraction ratios $<\mathbf{3 0 0}$ during the first $48 \mathrm{~h}$. Controls were matched to PP patients on the PP propensity score $( \pm 10 \%)$, MV duration longer than that in PP patients before the first turn prone, and centre.

VAP incidence was similar in the PP and control groups (24 versus 13 episodes 1,000 patientdays $M^{-1}$ respectively, $p=0.14$ ). After adjustment, PP did not decrease VAP occurrence (HR 1.64 $(95 \% \mathrm{Cl} 0.70-3.84) ; p=0.25)$ but significantly delayed hospital mortality (HR 0.56 (95\% Cl $0.39-$ 0.79 ); $p=0.001$ ), without decreasing 28 -day mortality (37\% in both groups). Post hoc analyses indicated that PP did not protect against VAP but, when used for $>1$ day, might decrease mortality and benefit the sickest patients (Simplified Acute Physiology Score $>50$ ).

In ICU patients with hypoxaemic acute respiratory failure, PP had no effect on the risk of VAP. PP delayed mortality without decreasing 28-day mortality. PP $>1$ day might decrease mortality, particularly in the sickest patients.

KEYWORDS: Acute lung injury, mortality, prone position, ventilator-associated pneumonia

$\mathbf{N}$ osocomial infections adversely affect patient outcomes, increase healthcare costs and generate difficult diagnostic and therapeutic challenges [1]. In the intensive care unit (ICU), ventilator-associated pneumonia (VAP) is the most common nosocomial infection, with $8-28 \%$ of patients on endotracheal mechanical ventilation (MV) being affected [2]. Mortality rates in patients with VAP have ranged from $24 \%$ to $50 \%$ [3]. Injured lungs are highly susceptible to infection, and acute respiratory distress syndrome (ARDS) is associated with a high rate of VAP [4-6]. Prone positioning (PP) has been used to improve oxygenation [7]. Despite the lack of conclusive evidence that PP improves patient outcomes, PP is used in hypoxaemic patients receiving MV for ARDS. No data are available on the rate of PP use in this population, even in the largest recent epidemiological studies [8, 9].

For editorial comments see page 725 .
In addition to improving oxygenation, PP has been shown in experimental studies to diminish ventilator-induced lung injury [10], and most clinicians agree that turning patients prone improves secretion drainage [11, 12]. Whether these effects protect against VAP is unclear. On the one hand, PP has been shown to enhance alveolar recruitment by avoiding atelectasis [13], which facilitates lung infection in experimental studies [14]; but on the other hand, PP may increase the dissemination of lung pathogens. In randomised controlled trials of PP in patients with acute lung injury (ALI)/ARDS, VAP rates are inconsistently reported [15] and, when available, vary across studies. Thus, in a study of 136 patients with severe ARDS, PP had no effect on VAP rates [16]; whereas in another study, conducted in 791 patients with hypoxaemic acute respiratory failure, VAP was slightly but significantly less common with PP [17].

The primary objective of this study was to clarify the effect of PP on VAP rates in ICU patients with
AFFILIATIONS

A full list of the authors' affiliations and the OUTCOMEREA Study Group members can be found in the Acknowledgements section.

CORRESPONDENCE

J-F. Timsit

Medical ICU

INSERM U823

Albert Michallon Teaching Hospital 38043 Grenoble CEDEX 9

France

E-mail: jf.timsit@outcomerea.org

Received:

April 062009

Accepted after revision:

Aug 242009

First published online:

Sept 092009 
ALI/ARDS. To this end, we used a large prospective database of ICU patients. We also compared mortality with and without PP.

\section{MATERIALS AND METHODS}

\section{Study design and data source}

We conducted a prospective observational study in the French OUTCOMEREA multicentre database over an 8-yr period (2000-2008). The database is specifically designed to record daily disease severity and the occurrence of iatrogenic events and nosocomial infections [1, 17-21]. Inclusion criteria for the study were MV for $\geqslant 2$ days, started within $48 \mathrm{~h}$ after ICU admission, with an arterial oxygen tension/inspiratory oxygen fraction ratio $\left(\mathrm{Pa}_{2} \mathrm{O}_{2} / \mathrm{FI}, \mathrm{O}_{2}\right) \leqslant 300$ during the first 2 days of MV with bilateral infiltrates with classic absence of clinical evidence of left atrial hypertension according to the protocol of each ICU. Patients ventilated at least once with PP (PP group) were compared to patients who were never turned prone while on MV (supine positioning (SP) group).

\section{Data collection}

Senior physicians in each participating ICU collected data daily. For each patient, the investigator entered the data into a computer case-report form using data capture software (RHEA, Rosny-sous-Bois, France) and imported all records to the OUTCOMEREA data warehouse. Data collection was approved by the CECIC Clermont Ferrand ethics committee (IRB no. 5891; Centre d'Investigation Clinique, CHU de Clermont Ferrand, France). The database is registered with the CNIL (Commission National Informatique et Liberté; Paris, France), an independent French administrative authority protecting privacy and personal data. All codes and definitions were established prior to study initiation. The following information was recorded for each patient: age and sex; admission category (medical, scheduled surgery or unscheduled surgery); origin (home, ward or emergency room); and McCabe score [22]. Severity of illness was evaluated on the first ICU day using the Simplified Acute Physiology Score II [23], the Sepsis-related Organ Failure Assessment (SOFA) score [24] and the Acute Physiologic and Chronic Health Evaluation II score [25]. Knaus scale definitions were used to record preexisting chronic organ failures including respiratory, cardiac, hepatic, renal and immune system failures [25].

Patient characteristics, treatment modalities (including MV, position, inotropic agents and antimicrobials), and invasive and noninvasive procedures were collected daily. MV duration, time in the ICU and hospital, and outcome at ICU and hospital discharge were recorded prospectively. Clinically suspected nosocomial pneumonia was routinely investigated using cultures of protected distal specimens, protected brushing or bronchoalveolar lavage, as previously described $[2,18]$.

\section{Quality of the database}

The data-capture software automatically conducted multiple checks for internal consistency of most of the variables at entry into the database. Queries generated by these checks were resolved with the source ICU before incorporation of the new data into the database. At each participating ICU, data quality was controlled by having a senior physician from another participating ICU check a $2 \%$ random sample of the study data.

\section{Procedures}

Because diagnostic coding has been found to be unreliable for identifying ALI/ARDS cases [26], we used parameters collected by our data-capture software to select patients with ALI/ARDS $\left(\mathrm{Pa}_{1} \mathrm{O}_{2} / \mathrm{FI}_{1} \mathrm{O}_{2}<200\right.$ or 300$)$. All ICUs followed the same rules for initiating $\mathrm{MV}$. In patients receiving $\mathrm{MV}$, tidal volume was set to maintain a plateau pressure of $<30 \mathrm{cmH}_{2} \mathrm{O}$ in most patients and $\leqslant 35 \mathrm{cmH}_{2} \mathrm{O}$ in all patients. PP (strictly horizontal) was left at the discretion of the attending physician. In all ICUs, PP protocols involved remaining prone for $>6 \mathrm{~h} \cdot \mathrm{day}^{-1}$. In both groups SP consisted of semi-recumbency unless the patient had refractory shock. Administration of stress ulcer prophylaxis and enteral feeding were at the discretion of the attending physician. None of the study ICUs used selective digestive tract decontamination or continuous aspiration of subglottic secretions.

\section{Statistical analysis}

Results are expressed as median (interquartile range) or $\mathrm{n}(\%)$ as appropriate. For categorical variables, comparisons were based on Chi-squared tests for categorical data and Wilcoxon tests for continuous data.

As the use of PP was not randomly assigned, we developed a PP-prediction model to compute a PP propensity score, which we then used to match patients managed with PP to controls managed with SP only. This matching procedure minimised treatment selection bias and potential confounding. The rationale and methods underlying the use of a propensity score for a proposed causal exposure variable have been described elsewhere $[19,27]$. The propensity score (probability that each patient would receive PP at any time during the ICU stay) was calculated by multivariate logistic regression using predictive variables collected within $48 \mathrm{~h}$ after ICU admission in the overall population.

Using an algorithm [28], we matched each control to a PP patient based on three characteristics (fig. 1): PP propensity score $( \pm 10 \%)$; MV duration greater than or equal to MV duration in the PP patient before the first turn prone; and centre. The propensity score was based on risk factors for PP. To take risk factors for VAP into account, we adjusted on imbalances between groups and risk factors for VAP. We then adjusted on the following: at admission, male sex, pneumonia, septic shock, acute respiratory failure and coma; within $48 \mathrm{~h}$ after ICU admission, vasoactive drugs; and on the day before PP (or the corresponding day in the SP group), antibiotic use, at least one catheter, SOFA score and $\mathrm{Pa}_{\mathrm{a}} \mathrm{O}_{2} / \mathrm{FI}_{1} \mathrm{O}_{2}$ ratio (table 1 ).

Assuming a 50\% rate of VAP in the PP group, 200 PP patients and 200 matched controls managed with SP only were needed to detect a hazard ratio (HR) of 2 for VAP with $>90 \%$ power and a type I error risk of 0.05 .

Imbalances between groups after matching were tested by conditional logistic regression. Comparisons between matched patients were based on a Cox model. The time of origin (T0) was defined as the beginning of PP in exposed patients and the equivalent time in matched controls (fig. 1). Only cases of pneumonia occurring between $\mathrm{T} 0$ and $48 \mathrm{~h}$ after MV discontinuation were considered. Data were censored at 28 days (starting at T0). Deaths within 28 days after T0 were taken 


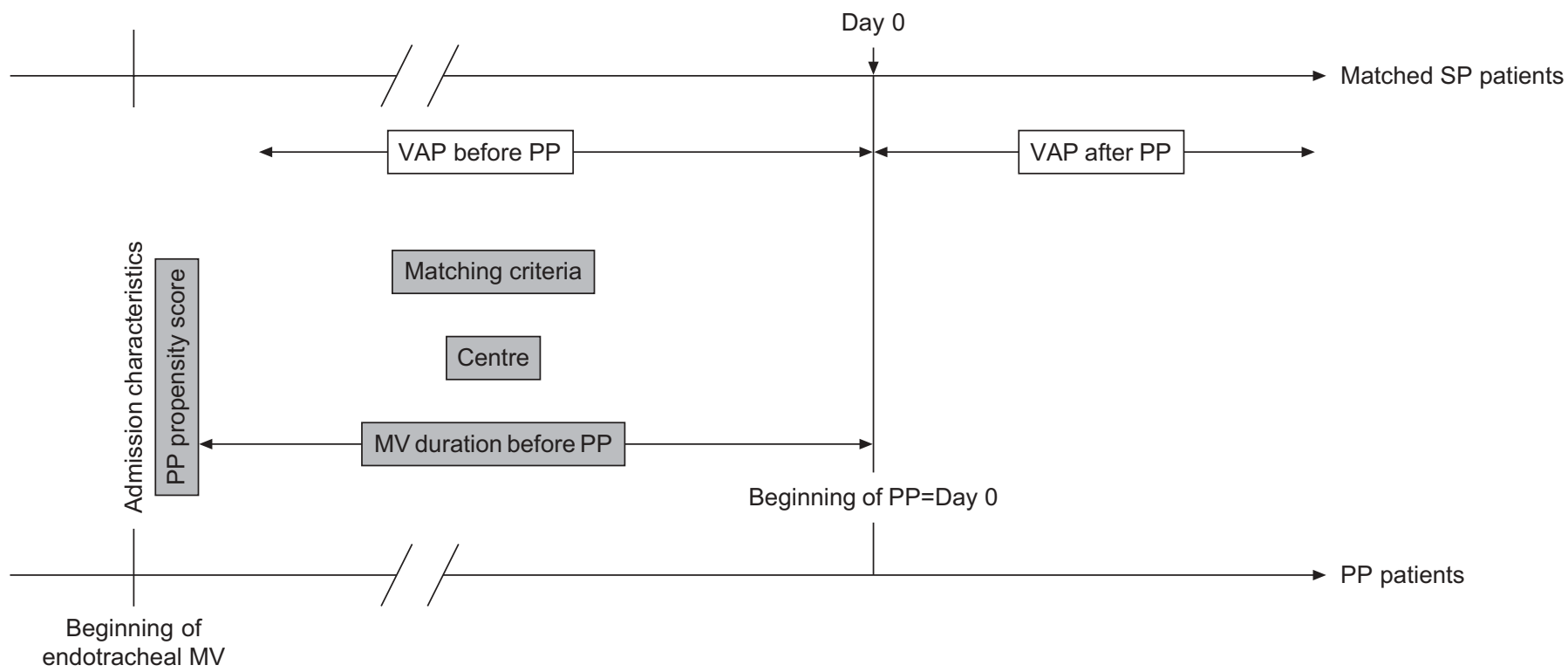

FIGURE 1. Diagram of the matching process. The matching criteria (denoted in grey) are: propensity score $\pm 10 \%$ calculated over the first $48 \mathrm{~h}$ after intensive care unit admission; centre; and mechanical ventilation (MV) duration before prone positioning (PP) in the PP group or on the corresponding day (day 0 ) in the supine positioning (SP) group. We calculated the number of patients with ventilator-associated pneumonia (VAP) after day 0.

into account. We used Kaplan-Meier plots to evaluate the risk of VAP and death in each group.

Risk factors for VAP and parameters that were not balanced between the PP and SP groups were used to estimate the adjusted HR of VAP using a marginal Cox model for clustered data. This model takes into account both the censored nature of the data and accounts for intra-cluster (intra-pair) dependence using a robust sandwich covariance estimate [29]. Values of $p \leqslant 0.05$ were considered significant. Analyses were computed using the SAS 9.1 software package (SAS Institute, Cary, NC, USA). Survival curves were drawn using $R$ ( $R$ Foundation, Vienna, Austria).

\section{RESULTS}

\section{Overall population of the database}

The study flow chart is shown in figure 2. Of the 2,409 included patients, $201(8 \%)$ received PP. Risk factors for VAP, selected based on data in the literature [2] and OUTCOMEREA database, were: male sex; pneumonia diagnosis at admission; chronic respiratory failure; acute respiratory failure at admission; septic shock at admission; use of vasoactive agents within the first $48 \mathrm{~h}$ in the ICU; temperature; cardiac frequency $(f \mathrm{C})$; $\mathrm{Pa}_{\mathrm{a}} \mathrm{O}_{2} / \mathrm{FI}_{1} \mathrm{O}_{2}$ ratio; and the need for an arterial catheter.

VAP occurred in $414(19 \%)$ out of 2,208 SP patients and 90 $(45 \%)$ out of 201 PP patients. Median duration of PP use was 1 day [1-3]. PP was significantly associated with longer MV duration compared to SP (19 (8-35) days versus 7 (4-13) days, $\mathrm{p}<0.0001)$, longer time in the ICU (25 (11-39) days versus 10 (517) days, $p<0.0001)$, and longer time in the hospital (41 (18-68) versus $24(12-43), p<0.0001)$. Mortality was higher in the PP group (95 (47\%) versus 777 (35\%) hospital deaths, $\mathrm{p}=0.0006)$.

Risk factors for PP in the overall population of 2,409 patients are listed in table 2. Predictors of PP at the final step of the multivariate logistic model (table 3) were male sex, coma,

\section{TABLE 1 Risk of ventilator-associated pneumonia (VAP) and death associated with prone positioning (PP)}

\begin{tabular}{|c|c|c|c|}
\hline & Event & HR $(95 \% \mathrm{Cl})$ & $\mathrm{p}$-value \\
\hline $\begin{array}{l}\text { After adjustment for confounding variables: imbalanced variables and } \\
\text { VAP risk factors }{ }^{\#}\end{array}$ & Pneumonia & $1.64(0.70-3.84)$ & 0.25 \\
\hline $\begin{array}{l}\text { After adjustment for confounding variables: imbalanced variables and } \\
\text { hospital risk factors }\end{array}$ & Death & $0.56(0.39-0.79)$ & 0.001 \\
\hline \multicolumn{4}{|c|}{ 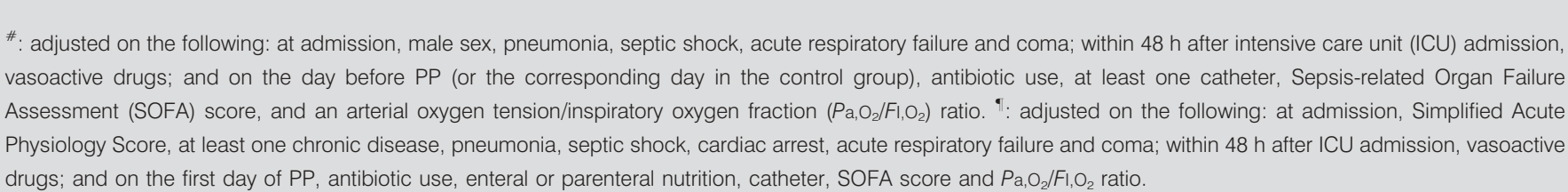 } \\
\hline
\end{tabular}




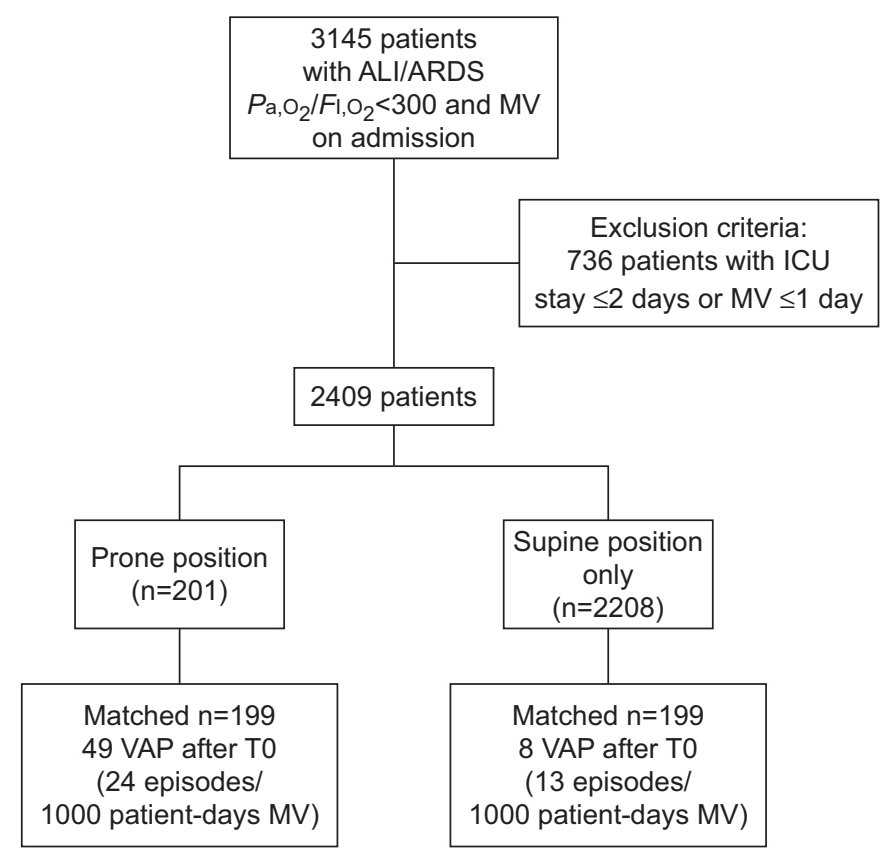

FIGURE 2. Flow chart of patients with acute lung injury/acute respiratory distress syndrome (ALI/ARDS) and matching procedure. $\mathrm{Pa}, \mathrm{O}_{2} / \mathrm{FI}, \mathrm{O}_{2}$ : ratio of arterial oxygen partial pressure over fraction of inspired oxygen; MV: endotracheal mechanical ventilation; ICU: intensive care unit; VAP: ventilator-associated pneumonia; TO: time of the first turn prone. There was no significant difference in VAP occurrence after TO between the groups with and without prone positioning (24 versus 13 VAP episodes 1,000 patient-days $\mathrm{MV}^{-1}$, respectively).

haemorrhagic shock, at least one catheter, core temperature $\geqslant 38.2^{\circ} \mathrm{C}, f \mathrm{C} \geqslant 120 \mathrm{bpm}$, prothrombin time $\leqslant 65 \mathrm{~s}$, and $\mathrm{Pa}_{\mathrm{a}} \mathrm{O}_{2} /$ $\mathrm{FI}, \mathrm{O}_{2}$ ratio range within the first $48 \mathrm{~h}$ in the ICU. Matching on propensity score, severity and centre was successful for 199 PP and 199 SP patients.

The Hosmer-Lemeshow of $3.7(p=0.89)$ indicated good fit of the data, and discrimination was good (area under the receiver-operating characteristics curve 0.74).

We performed stepwise logistic regression with a 5\% threshold on all risk factors for PP identified in the univariate analyses: male sex; transfer from ward; admission diagnosis of pneumonia; admission diagnosis of acute respiratory failure; chronic cirrhosis; acute respiratory failure at admission; coma at admission; haemorrhagic shock at admission; use of vasoactive drugs, steroids, or enteral nutrition within $48 \mathrm{~h}$ after ICU admission; at least one catheter within $48 \mathrm{~h}$ after ICU admission; and categories of temperature, $f C$, prothrombin time, and $\mathrm{Pa}, \mathrm{O}_{2} / F \mathrm{I}, \mathrm{O}_{2}$ ratio within $48 \mathrm{~h}$ after ICU admission.

To calculate the predicted risk for PP in an individual patient: 1) compute the logit: logit=sum ("Beta estimate" multiplied by value of corresponding parameter); then 2) compute the probability, using the logit: $\mathrm{p}=(\exp$ (logit) $)$ divided by $(1+\exp (\log i t))$.

\section{Case-control analysis}

Parameters that were not balanced between the SP and PP groups (table 4) were as follows: 1) at ICU admission, pneumonia, septic shock, acute respiratory failure, coma and lowest $\mathrm{Pa}, \mathrm{O}_{2} / \mathrm{FI}, \mathrm{O}_{2}$ ratio; 2) during the first $48 \mathrm{~h}$ of $\mathrm{MV}$, use of vasoactive agents and use of at least one catheter; and 3) on the day before PP (or the corresponding day in the SP group), use of antibiotics, use of at least one catheter, lowest $\mathrm{Pa}_{2} \mathrm{O}_{2} / \mathrm{FI}, \mathrm{O}_{2}$ ratio and SOFA score. The median time from ICU admission to PP was 6 days [2-12]. The median time spent in the ICU after T0 was longer in the PP group than in the SP group (14 (6-29) days versus 3 (1-8) days, $\mathrm{p}<0.0001)$.

\section{Risk of VAP}

There were 57 episodes of VAP after T0. The incidence of VAP after T0 was not significantly different between the PP and SP groups (24 versus 13 episodes $\cdot 1,000$ patient-days $\mathrm{MV}^{-1}$, $\mathrm{p}=0.14)$. The most common causative microorganisms were Pseudomonas aeruginosa $(\mathrm{n}=20 ; 35 \%)$, Enterobacteriaceae $(\mathrm{n}=12$, $21 \%)$, Escherichia coli $(\mathrm{n}=10,18 \%)$ and Staphylococcus aureus $(\mathrm{n}=9,16 \%)$. The rate of multidrug-resistant bacteria was balanced between the two groups.

PP did not influence the VAP risk (HR 1.33 (95\% CI 0.61-2.92), $\mathrm{p}=0.48$ ). Results (table 1 ) were unchanged after adjusting on risk factors for VAP and imbalances between groups (HR 1.64 (95\% CI 0.70-3.84), $\mathrm{p}=0.25$ ) (fig. 3).

We assessed the impact of PP duration by separately evaluating patients in each quartile of time with PP. Among 109 patients with a single day of PP (with 109 matched SP patients), PP was not associated with VAP (HR 1.11 (95\% CI $0.39-3.10), p=0.85)$. Neither did the 90 patients with at least 2 days of PP have a lower rate of VAP compared to the 90 matched SP patients (HR 0.72 (95\% CI 0.32-1.65), $\mathrm{p}=0.44)$.

\section{Mortality}

When we used the marginal Cox model with adjustment on risk factors for hospital death and imbalances between groups, we found that PP significantly delayed hospital mortality (HR 0.56 (95\% CI 0.39-0.79), p=0.001) (fig. 4 and table 1). However, mortality 28 days after T0 was similar in the PP group $(n=73$, $36.7 \%)$ and in the SP group $(n=74,37.2 \%)$. Among patients with a single day of PP $(n=109)$, mortality was not different from that in the matched controls (HR 0.83 (95\% CI 0.51-1.35), $\mathrm{p}=0.45$ ). In contrast, adjusted mortality in the 90 patients with $\geqslant 2$ days of PP was significantly lower than in the matched controls $(27(30 \%)$ in the PP group versus $38(42 \%)$ in the controls; HR 0.30 (95\% CI 0.12-0.74), $\mathrm{p}=0.009)$.

\section{ARDS patients}

When we confined the analysis to patients with $\mathrm{Pa}_{\mathrm{a}} \mathrm{O}_{2} / \mathrm{FI}_{1} \mathrm{O}_{2}$ ratios $<200$ at admission (i.e. ARDS), we were able to obtain 155 PP-control pairs matched on the PP propensity score, severity and centre. In this analysis, PP was not associated with the VAP risk (adjusted HR 1.03 (95\% CI 0.42-2.56), $\mathrm{p}=0.94)$ or the risk of death (adjusted HR 0.90 (95\% CI 0.61-1.32), $\mathrm{p}=0.58$ ).

\section{Subgroup analyses}

In the overall population of $398 \mathrm{ALI} / \mathrm{ARDS}$ patients (tables 5 and 6), 104 patients had $\mathrm{Pa}_{1} \mathrm{O}_{2} / \mathrm{FI}, \mathrm{O}_{2}$ ratios $<120$ within 2 days before $\mathrm{PP}$ (or the corresponding time in the control group). Among them, 72 received PP and 32 were controls. VAP occurred in 20 $(27.8 \%)$ PP patients and two $(6.3 \%)$ controls. Of the PP patients, $32(44.4 \%)$ died, compared to $20(62.5 \%)$ controls. After 


\begin{tabular}{|c|c|c|c|c|}
\hline \multirow{2}{*}{$\begin{array}{l}\text { TABLE } 2 \\
\text { Variables }\end{array}$} & \multicolumn{4}{|c|}{$\begin{array}{l}\text { Risk factors for prone positioning (PP) in } 2,409 \\
\text { patients who received endotracheal mechanical } \\
\text { ventilation }(\mathrm{MV}) \text { within } 48 \mathrm{~h} \text { after intensive care } \\
\text { unit (ICU) admission, for } \geqslant 2 \text { days, and who had } \\
\text { arterial oxygen tension/inspiratory oxygen } \\
\text { fraction }\left(\mathrm{Pa}, \mathrm{O}_{2} / \mathrm{FI}_{1} \mathrm{O}_{2}\right) \text { ratios }<300 \text { during the first } \\
48 \mathrm{~h} \text { on } \mathrm{MV}\end{array}$} \\
\hline & & SP & PP & p-value \\
\hline Patients n & & 2208 & 201 & \\
\hline Age yrs & & $66(54-76)$ & $65(50-75)$ & 0.04 \\
\hline Males & & $1411(63.9)$ & $150(74.6)$ & 0.002 \\
\hline Transfer fror & ward & $1055(47.8)$ & $112(55.7)$ & 0.03 \\
\hline \multicolumn{5}{|c|}{ Severity scores at admission } \\
\hline SAPS ॥ & & $52(40-64)$ & $51(40-65)$ & 0.85 \\
\hline APACHE ॥ & core & $20(15-25)$ & $20(15-25)$ & 0.64 \\
\hline SOFA scor & & $7(5-10)$ & $7(5-11)$ & 0.79 \\
\hline \multicolumn{5}{|c|}{ Immunosuppression } \\
\hline Chemother & & $138(6.3)$ & $10(5)$ & 0.47 \\
\hline $\begin{array}{l}\text { Steroid the } \\
>2 \mathrm{mg} \cdot \mathrm{k}\end{array}$ & $\begin{array}{l}\text { py }>1 \text { month or } \\
-1\end{array}$ & $82(3.7)$ & $11(5.5)$ & 0.22 \\
\hline AIDS & & $45(2)$ & $2(1)$ & 0.31 \\
\hline Bone marrc & vaplasia & $33(1.5)$ & $4(2)$ & 0.59 \\
\hline \multicolumn{5}{|c|}{ Diagnosis at admission } \\
\hline Pneumonia & & $450(20.4)$ & $63(31.3)$ & 0.0003 \\
\hline Septic sho & & 249 (11.3) & $31(15.4)$ & 0.08 \\
\hline Cardiac arr & & $181(8.2)$ & $4(2)$ & 0.002 \\
\hline Acute resp & atory failure & $130(5.9)$ & $24(11.9)$ & 0.001 \\
\hline Stroke & & $124(5.6)$ & $7(3.5)$ & 0.20 \\
\hline Acute renal & ailure & $94(4.3)$ & $3(1.5)$ & 0.06 \\
\hline COPD exac & rbation & $78(3.5)$ & $5(2.5)$ & 0.44 \\
\hline Cardiogeni & pulmonary oedema & $66(3)$ & $5(2.5)$ & 0.69 \\
\hline Multiple ors & in failure & $34(1.5)$ & $7(3.5)$ & 0.04 \\
\hline \multicolumn{5}{|c|}{ Admission category ${ }^{\#}$} \\
\hline Medical & & $1562(71)$ & $135(67.5)$ & \\
\hline Emergency & urgery & $406(18.4)$ & $36(18)$ & 0.23 \\
\hline Scheduled & urgery & $233(10.6)$ & $29(14.5)$ & \\
\hline \multicolumn{5}{|c|}{ Previous health status (McCabe) } \\
\hline Not fatal & & $1267(57.4)$ & $118(58.7)$ & \\
\hline Fatal within & yrs & $730(33.1)$ & 69 (34.3) & 0.48 \\
\hline Fatal within & & $211(9.6)$ & $14(7)$ & \\
\hline \multicolumn{5}{|c|}{ Comorbidities } \\
\hline Immunosup & ression & $274(12.4)$ & $29(14.4)$ & 0.41 \\
\hline Respiratory & ailure & $383(17.3)$ & $42(20.9)$ & 0.21 \\
\hline Cardiovasc & ar failure & $344(15.6)$ & $26(12.9)$ & 0.32 \\
\hline Cirrhosis & & $143(6.5)$ & $21(10.4)$ & 0.03 \\
\hline Renal failur & & $103(4.7)$ & $9(4.5)$ & 0.90 \\
\hline At least on & chronic disease & $962(43.6)$ & 99 (49.3) & 0.12 \\
\hline \multicolumn{5}{|c|}{ Main symptom at admission } \\
\hline Acute respi & tory failure & $623(28.2)$ & $71(35.3)$ & 0.03 \\
\hline Coma & & $520(23.6)$ & $17(8.5)$ & $<0.0001$ \\
\hline Septic sho & & $407(18.4)$ & 40 (19.9) & 0.61 \\
\hline Multiple ors & in failure & $73(3.3)$ & $11(5.5)$ & 0.11 \\
\hline Cardiogeni & shock & $101(4.6)$ & $6(3)$ & 0.30 \\
\hline Haemorrha & c shock & $89(4)$ & $20(10)$ & 0.0001 \\
\hline Monitoring & d scheduled surgery & $202(9.1)$ & $15(7.5)$ & 0.42 \\
\hline COPD exac & rbation & $53(2.4)$ & $8(4)$ & 0.17 \\
\hline Acute renal & ailure & $34(1.5)$ & $6(3)$ & 0.12 \\
\hline Trauma & & $21(1)$ & $3(1.5)$ & 0.46 \\
\hline
\end{tabular}

\begin{tabular}{|c|c|c|c|}
\hline \multicolumn{4}{|c|}{ TABLE 2 Continued } \\
\hline Variables & SP & PP & p-value \\
\hline \multicolumn{4}{|c|}{ Treatment during the first $48 \mathrm{~h}$} \\
\hline Vasoactive drugs & $1413(64)$ & $156(77.6)$ & 0.0001 \\
\hline Steroids & $680(30.8)$ & $76(37.8)$ & 0.04 \\
\hline Antibiotics & $1753(79.4)$ & $169(84.1)$ & 0.11 \\
\hline Enteral nutrition & $566(25.6)$ & $35(17.4)$ & 0.01 \\
\hline Parenteral nutrition & $385(17.4)$ & $45(22.4)$ & 0.08 \\
\hline \multicolumn{4}{|c|}{ Procedures during the first $48 \mathrm{~h}$} \\
\hline Arterial catheter & $1119(50.7)$ & $126(62.7)$ & 0.001 \\
\hline Central catheter & $1403(63.5)$ & $162(80.6)$ & 0.0001 \\
\hline Swan catheter & $107(4.8)$ & $20(10)$ & 0.002 \\
\hline At least one catheter & $1482(67.1)$ & $170(84.6)$ & $<0.0001^{4}$ \\
\hline \multicolumn{4}{|c|}{$\begin{array}{l}\text { Laboratory variables in the } \\
\text { first } 48 \mathrm{~h}\end{array}$} \\
\hline Temperature $\max { }^{\circ} \mathrm{C}$ & $38.2(37.7-38.9)$ & $38.6(38-39.2)$ & $<0.0001$ \\
\hline fC max bpm & $116(100-135)$ & $126(108-144)$ & $<0.0001$ \\
\hline Prothrombin rate max \% & $69(55-80)$ & $61(49-74)$ & $<0.0001$ \\
\hline Lowest $\mathrm{Pa}, \mathrm{O}_{2} / \mathrm{Fl}, \mathrm{O}_{2}$ ratio & $165.5(112-220)$ & $129(85-193)$ & $<0.0001$ \\
\hline \multicolumn{4}{|c|}{$\begin{array}{l}\text { Laboratory variables in the first } \\
48 \mathrm{~h} \text { in categories }\end{array}$} \\
\hline Temperature $\geqslant 38.2^{\circ} \mathrm{C}$ & $1146(51.9)$ & $144(71.6)$ & $<0.0001$ \\
\hline$f C \geqslant 120 \mathrm{bpm}$ & $1027(46.5)$ & $128(63.7)$ & $<0.0001$ \\
\hline Prothrombin rate $\leqslant 65 \%$ & $917(41.5)$ & $117(58.2)$ & $<0.0001$ \\
\hline \multicolumn{4}{|l|}{$\mathrm{Pa}_{1} \mathrm{O}_{2} / \mathrm{Fl}_{1} \mathrm{O}_{2}$ ratio } \\
\hline$<100$ & $436(19.7)$ & $73(36.3)$ & $<0.0001$ \\
\hline 100-159 & $600(27.2)$ & $57(28.4)$ & \\
\hline 160-219 & $614(27.8)$ & 39 (19.4) & \\
\hline 220-299 & $558(25.3)$ & 32 (15.9) & \\
\hline
\end{tabular}

Data are presented as $n(\%)$ or median (interquartile range), unless otherwise stated. SP: supine position; SAPS II: Simplified Acute Physiology Score II; APACHE II: Acute Physiology and Chronic Health Evaluation II; SOFA: Sequential Organ Failure Assessment; COPD: chronic obstructive pulmonary disease; fc: cardiac frequency. ${ }^{*}$ : data are missing for eight patients; " evaluated using the APACHE II score (Knaus criteria). Variables within the first $48 \mathrm{~h}$ in the ICU were obtained as follows: in patients who received PP on the first ICU day, we only used the worst data collected on day 0 ; in patients who received MV on the second ICU day (day 1), we used the worst data collected on day 1 ; and in patients who received MV on the first ICU day (day 0), we used the worst data collected between day 0 and day 1 .

adjustment on imbalances between groups and risk factors for events, PP was associated neither with VAP (HR 0.69 (95\% CI $0.19-2.52), p=0.57$ ) nor with death (HR 0.56 (95\% CI 0.29-1.09), $\mathrm{p}=0.09$ ).

Among 114 patients with SAPS II score values $>50$ on the day of the first turn prone (or the corresponding day in controls), 64 received PP and 50 were controls. VAP occurred in $11(17 \%)$ PP patients and one (2\%) control. Of the PP patients, $41(64 \%)$ died, compared to $39(78 \%)$ of the controls. After adjustment on imbalances between groups and risk factors for events, PP was not associated with VAP (HR 4.33 (95\% CI 0.70-26.65), $\mathrm{p}=0.11$ ) but was significantly and negatively associated with hospital death (HR 0.44 (95\% CI 0.29-0.69), p=0.0003) (tables 5 and 6). 


\begin{tabular}{|c|c|c|c|}
\hline \multirow{2}{*}{$\begin{array}{l}\text { TABLE } 3 \\
\text { Intercept }\end{array}$} & \multicolumn{3}{|c|}{$\begin{array}{l}\text { Predictors of prone positioning (PP) at the final } \\
\text { step of the multivariate logistic model }\end{array}$} \\
\hline & & Estimator & OR $(95 \% \mathrm{Cl})$ \\
\hline \multicolumn{2}{|l|}{ Male } & 0.4377 & $1.55(1.10-2.18)$ \\
\hline \multicolumn{2}{|l|}{ Coma } & -0.8015 & $0.45(0.27-0.76)$ \\
\hline \multicolumn{2}{|c|}{ Haemorrhagic shock } & 0.9845 & $2.68(1.56-4.60)$ \\
\hline \multicolumn{4}{|c|}{ Variables collected within the first $48 \mathrm{~h}^{\#}$} \\
\hline \multicolumn{2}{|c|}{ At least one catheter } & 0.6325 & $1.88(1.25-2.84)$ \\
\hline \multicolumn{2}{|c|}{ Temperature $\geqslant 38.2^{\circ} \mathrm{C}$} & 0.8655 & $2.38(1.70-3.31)$ \\
\hline \multicolumn{2}{|c|}{$f \mathrm{C} \geqslant 120 \mathrm{bpm}$} & 0.4157 & $1.52(1.11-2.08)$ \\
\hline \multicolumn{2}{|c|}{ Prothrombin rate $\leqslant 65 \%$} & 0.4966 & $1.64(1.21-2.24)$ \\
\hline \multicolumn{4}{|c|}{${\mathrm{Pa}, \mathrm{O}_{2} / \mathrm{F} 1, \mathrm{O}_{2} \text { ratio }}^{\#}$} \\
\hline \multicolumn{2}{|l|}{$<100$} & 0.8611 & $2.37(1.51-3.71)$ \\
\hline \multicolumn{2}{|l|}{$100-159$} & 0.3551 & $1.43(0.90-2.26)$ \\
\hline \multicolumn{2}{|l|}{$160-219$} & -0.0767 & $0.93(0.57-1.52)$ \\
\hline \multicolumn{2}{|l|}{ 220-299 } & & \\
\hline
\end{tabular}

fC: cardiac frequency; $\mathrm{Pa}_{2} \mathrm{O}_{2} / \mathrm{Fl}_{1} \mathrm{O}_{2}$ : arterial oxygen tension/inspiratory oxygen fraction ratio. ${ }^{\#}$ : variables collected within the first $48 \mathrm{~h}$ after intensive care unit (ICU) admission. Variables within the first $48 \mathrm{~h}$ in the ICU were obtained as follows: in patients who received PP on the first ICU day, we only used the worst data collected on day 0 ; in patients who received mechanical ventilation (MV) on the second ICU day (day 1), we used the worst data on day 1 ; and in patients who received MV on the first ICU day (day 0), we used the worst data collected between day 0 and day 1 .

\section{DISCUSSION}

We found that PP was used in $8 \%$ of ALI/ARDS patients with $\mathrm{Pa}_{1} \mathrm{O}_{2} / \mathrm{FI}, \mathrm{O}_{2}$ ratio values $<300$ while receiving $\mathrm{MV}$. In the overall population, PP failed to protect against VAP or death.

Although PP was described more than 30 yrs ago [30], very few data are available on the rate of PP use outside the setting of physiological studies or randomised controlled trials. In a study describing the management of ARDS over an 8-yr period in a single ICU, PP was used in $4 \%$ of ARDS patients during the first half of the study period and in $25 \%$ during the second half after routine $\mathrm{PP}$ use in the sickest patients was incorporated into the standard management protocol [31]. These proportions are consistent with our finding that $8 \%$ of patients were turned prone at least once during the ICU stay.

Numerous physiological and clinical studies have shown that PP improves oxygenation [7] by homogenising the pleural pressure gradient and increasing ventilation to the dorsal areas of the lungs. PP may also reduce lung overdistension [32] and improve alveolar ventilation and lung mechanics, thereby preventing or lessening ventilator-induced lung injury [10]. In addition, PP improves secretion drainage, which is often impaired in intubated patients. These effects would be expected to translate into a decreased risk of VAP [12].

The VAP rate was a secondary evaluation criterion in three randomised controlled trials comparing PP and SP [16, 17, 33]. Only one of these trials found that PP protected against VAP as a secondary end-point [17]. Another study [33] evaluated the effect of PP on the lung injury score and on the development of $\mathrm{VAP}$ as a secondary criterion in 51 comatose patients receiving
MV. Patients in the treatment group were turned prone for $4 \mathrm{~h}$ once a day, starting early during the ICU stay. The diagnosis of VAP relied on quantitative cultures from bronchoscopic protected-specimen brush samples. In this relatively small study, PP was associated with less deterioration in the lung score, but VAP rates were not significantly different between groups (20\% with PP versus 38\% with SP, p=0.14) [33]. In addition, patients kept supine had their head and trunk elevated at $20^{\circ}$ instead of being placed in the semi-recumbent position (at least $30^{\circ}$ of head-of-bed elevation). The other study that found no effect of PP on the VAP rate was conducted in 136 patients with severe ARDS [16]. PP was started early and used for most of the day. There was no difference in VAP rates between the PP and SP groups. In the largest study $(n=791)$, PP did not affect mortality but decreased the rate of VAP [17]. This study included medical and surgical patients with acute hypoxaemic respiratory failure. PP was started early after intubation and used for a mean of $8.6 \mathrm{~h} \cdot$ days $^{-1}$ for a mean of 4.1 days. The diagnosis of VAP was based on quantitative cultures of bronchoalveolar lavage fluid. The VAP rate per 100 patientdays of intubation was 1.66 with PP and 2.14 with SP $(p=0.045)$.

The $21 \%$ VAP rate in our cohort of 2,409 patients is consistent with previous data [2]. The VAP incidence rate of 24 per 1,000 MV-days in our PP group is only slightly higher than the rate in PP patients in the largest randomised controlled study [17], and crude mortality rates are similar ( $31 \%$ and $36 \%$ respectively). However, the prevalence of VAP in our study was lower than hypothesised, which decreased the power of the study.

PP duration in our study was considerably shorter, than in previous studies probably because no uniform PP protocol was used. However, our data shed light on outcomes in everyday practice. We identified several risk factors for PP: admission diagnosis of ARDS or pneumonia; shock at admission; vasoactive drug use; low $\mathrm{Pa}, \mathrm{O}_{2} / \mathrm{FI}_{1} \mathrm{O}_{2}$ ratio; and prolonged $\mathrm{MV}$.

PP is widely believed to improve bronchial secretion drainage, thereby limiting colonisation of the distal lung, an effect expected to decrease the risk of VAP. However, other effects of PP may increase the risk for VAP. Once patients are turned prone, they are in the horizontal position, which may be associated with a higher risk of aspiration than the semirecumbent supine position [34], particularly in patients receiving enteral feeding [35]. PP has also been associated with greater residual gastric volumes and poorer tolerance of enteral nutrition, which in turn are associated with a higher risk of VAP [36]. Data from a $P$. aeruginosa unilateral pneumonia mouse model suggest that PP may promote the dissemination of localised infection to the contralateral lung [37]. Finally, the influence of PP on the VAP risk may vary with the timing of PP relative to MV initiation. When PP is started $>3$ days after MV initiation the distal airways may already be colonised [38, 39] and, therefore, potential benefits from improved secretion drainage may be lost.

Although PP dramatically increased oxygenation in severely hypoxaemic patients [15-17, 38, 40-42], no effect on mortality was found in randomised controlled trials. Similarly, our results do not support the routine use of PP in patients on MV whose $\mathrm{Pa}_{1} \mathrm{O}_{2} / \mathrm{FI}, \mathrm{O}_{2}$ ratio is $<300$. Furthermore, they suggest that a longer 


\begin{tabular}{|c|c|c|c|c|}
\hline \multirow{2}{*}{$\begin{array}{l}\text { TABLE } 4 \\
\text { Variables }\end{array}$} & \multicolumn{4}{|c|}{$\begin{array}{l}\text { Comparison of patients treated with prone } \\
\text { positioning (PP) and individually matched } \\
\text { patients kept in the supine position (SP) }\end{array}$} \\
\hline & & SP & PP & p-value \\
\hline \multicolumn{2}{|l|}{ Subjects $n$} & 199 & 199 & \\
\hline \multicolumn{2}{|l|}{ Age yrs } & $66(54-76)$ & $65(50-75)$ & 0.24 \\
\hline \multicolumn{2}{|l|}{ Males } & $133(66.8)$ & $149(74.9)$ & 0.08 \\
\hline \multicolumn{2}{|c|}{ Transfer from ward } & $95(47.7)$ & $110(55.3)$ & 0.12 \\
\hline \multicolumn{5}{|c|}{ Severity scores at admission } \\
\hline \multicolumn{2}{|l|}{ SAPS ॥ } & $52(37-64)$ & $51(40-66)$ & 0.79 \\
\hline \multicolumn{2}{|c|}{ APACHE I| score } & $20(16-25)$ & $19(15-25)$ & 0.59 \\
\hline \multicolumn{2}{|c|}{ SOFA score } & $7(5-10)$ & $7(5-11)$ & 0.65 \\
\hline \multicolumn{5}{|c|}{ Immunosuppression } \\
\hline \multicolumn{2}{|c|}{ Chemotherapy } & $11(5.5)$ & $9(4.5)$ & 0.64 \\
\hline \multicolumn{2}{|c|}{$\begin{array}{l}\text { Steroid therapy }>1 \text { month or } \\
>2 \mathrm{mg} \cdot \mathrm{kg}^{-1}\end{array}$} & $9(4.5)$ & $11(5.5)$ & 0.66 \\
\hline \multicolumn{2}{|l|}{ AIDS } & $7(3.5)$ & $2(1)$ & 0.12 \\
\hline \multicolumn{2}{|c|}{ Bone marrow aplasia } & $5(2.5)$ & $3(1.5)$ & 0.43 \\
\hline \multicolumn{5}{|c|}{ Diagnosis at admission } \\
\hline \multicolumn{2}{|c|}{ Pneumonia } & 39 (19.6) & $63(31.7)$ & 0.006 \\
\hline \multicolumn{2}{|c|}{ Septic shock } & $16(8)$ & $30(15.1)$ & 0.02 \\
\hline \multicolumn{2}{|c|}{ Acute respiratory failure } & $13(6.5)$ & $24(12.1)$ & 0.08 \\
\hline \multicolumn{2}{|l|}{ Stroke } & $9(4.5)$ & $7(3.5)$ & 0.62 \\
\hline Acute rena & ailure & $9(4.5)$ & $3(1.5)$ & 0.10 \\
\hline COPD exa & rbation & $9(4.5)$ & $5(2.5)$ & 0.29 \\
\hline Cardiogen & pulmonary oedema & $7(3.5)$ & $5(2.5)$ & 0.57 \\
\hline Multiple or & $n$ failure & $7(3.5)$ & $7(3.5)$ & 1.00 \\
\hline Admission & tegory $\#$ & & & \\
\hline Medical & & $138(69.7)$ & $134(67.7)$ & \\
\hline Emergenc) & urgery & $36(18.2)$ & $35(17.7)$ & 0.75 \\
\hline Scheduled & urgery & $24(12.1)$ & 29 (14.6) & \\
\hline Previous he & th status (McCabe) & & & \\
\hline Not fatal & & $108(54.3)$ & $117(58.8)$ & \\
\hline Fatal withir & yrs & 64 (32.2) & $68(34.2)$ & 0.14 \\
\hline Fatal withir & & 27 (13.6) & $14(7)$ & \\
\hline Comorbiditi & & & & \\
\hline Immunosu & ression & $26(13.1)$ & $28(14.1)$ & 0.74 \\
\hline Respiratory & ailure & $36(18.1)$ & $42(21.1)$ & 0.42 \\
\hline Cardiovasc & ar failure & $36(18.1)$ & $26(13.1)$ & 0.18 \\
\hline Cirrhosis & & $17(8.5)$ & $21(10.6)$ & 0.51 \\
\hline Renal failu & & $6(3)$ & $9(4.5)$ & 0.44 \\
\hline At least on & chronic disease & $94(47.2)$ & 98 (49.2) & 0.68 \\
\hline Main sympt & at admission & & & \\
\hline Acute resp & tory failure & $42(21.1)$ & $71(35.7)$ & 0.002 \\
\hline Coma & & $58(29.1)$ & $17(8.5)$ & $<0.0001$ \\
\hline Septic sho & & $32(16.1)$ & 39 (19.6) & 0.36 \\
\hline Multiple or & $n$ failure & $11(5.5)$ & $11(5.5)$ & 1.00 \\
\hline Cardiogen & shock & $6(3)$ & $6(3)$ & 1.00 \\
\hline Haemorrha & c shock & $15(7.5)$ & $19(9.5)$ & 0.47 \\
\hline Monitoring & ad scheduled surgery & $22(11.1)$ & $15(7.5)$ & 0.23 \\
\hline COPD exa & rbation & $5(2.5)$ & $8(4)$ & 0.41 \\
\hline Acute rena & ailure & 0 & $6(3)$ & 0.99 \\
\hline Trauma & & $3(1.5)$ & $3(1.5)$ & 1.00 \\
\hline $\begin{array}{r}\text { Lowest } P \mathrm{a}, \mathrm{O} \\
48 \mathrm{~h} \text { aft }\end{array}$ & $\begin{array}{l}\mathrm{I}_{1} \mathrm{O}_{2} \text { ratio within } \\
\mathrm{ICU} \text { admission }\end{array}$ & $154(96-220)$ & $130(85-194)$ & 0.006 \\
\hline Treatment $\mathrm{c}$ & ing the first $48 h$ & & & \\
\hline Vasoactive & rugs & $124(62.3)$ & $154(77.4)$ & 0.0009 \\
\hline Steroids & & $68(34.2)$ & $75(37.7)$ & 0.44 \\
\hline
\end{tabular}

\begin{tabular}{|c|c|c|c|}
\hline Continued & & & \\
\hline Variables & SP & PP & $\mathrm{p}$-value \\
\hline Antibiotics & $152(76.4)$ & $168(84.4)$ & 0.05 \\
\hline Enteral nutrition & $46(23.1)$ & $35(17.6)$ & 0.17 \\
\hline Parenteral nutrition & $43(21.6)$ & $44(22.1)$ & 0.90 \\
\hline \multicolumn{4}{|l|}{ Procedures during the first $48 \mathrm{~h}$} \\
\hline Arterial catheter & $98(49.2)$ & $124(62.3)$ & 0.004 \\
\hline Central catheter & $116(58.3)$ & $160(80.4)$ & $<0.0001$ \\
\hline Swan catheter & $13(6.5)$ & $20(10.1)$ & 0.23 \\
\hline At least one catheter & $125(62.8)$ & $168(84.4)$ & $<0.0001$ \\
\hline \multicolumn{4}{|l|}{$\begin{array}{l}\text { Variables collected on the day } \\
\text { before PP }\end{array}$} \\
\hline Antibiotics & $128(64.3)$ & $163(81.9)$ & 0.0001 \\
\hline At least one catheter & $113(56.8)$ & $162(81.4)$ & $<0.0001$ \\
\hline $\mathrm{Pa}_{1} \mathrm{O}_{2} / \mathrm{Fl}, \mathrm{O}_{2}$ ratio & $254(185-337)$ & $193(121-296)$ & $<0.0001$ \\
\hline SOFA & $5(4-9)$ & $7(5-10)$ & 0.005 \\
\hline \multicolumn{4}{|c|}{$\begin{array}{l}\text { Data are presented as } \mathrm{n}(\%) \text { or median (interquarile range), unless otherwise } \\
\text { stated. SAPS II: Simplified Acute Physiology Score II; APACHE ॥: Acute } \\
\text { Physiology and Chronic Health Evaluation II; SOFA: Sequential Organ Failure } \\
\text { Assessment; COPD: chronic obstructive pulmonary disease; } \mathrm{Pa}, \mathrm{O}_{2} / \mathrm{Fl}, \mathrm{O}_{2}: \text { arterial } \\
\text { oxygen tension/inspiratory oxygen fraction ratio; ICU: intensive care unit. }{ }^{\#} \text { : } \\
\text { data are missing for two patients; ": evaluated using the APACHE ॥ score } \\
\text { (Knaus criteria). The p-values were obtained by conditional logistic regression. }\end{array}$} \\
\hline
\end{tabular}

time spent in the prone position does not increase the incidence of VAP. That PP does not affect mortality may be ascribable to the major contribution of sepsis and multiorgan failure to mortality in ARDS patients, as opposed to respiratory disease [43] the use of unproven rescue treatments (inhaled nitric oxide or prone position) may be used as a rescue therapy in patients with refractory hypoxaemia [15, 40, 43].

Interestingly, post hoc subgroup analyses performed by GATTINONI et al. [15] identified a subgroup in which PP was associated with a significant decrease in 10-day mortality. This

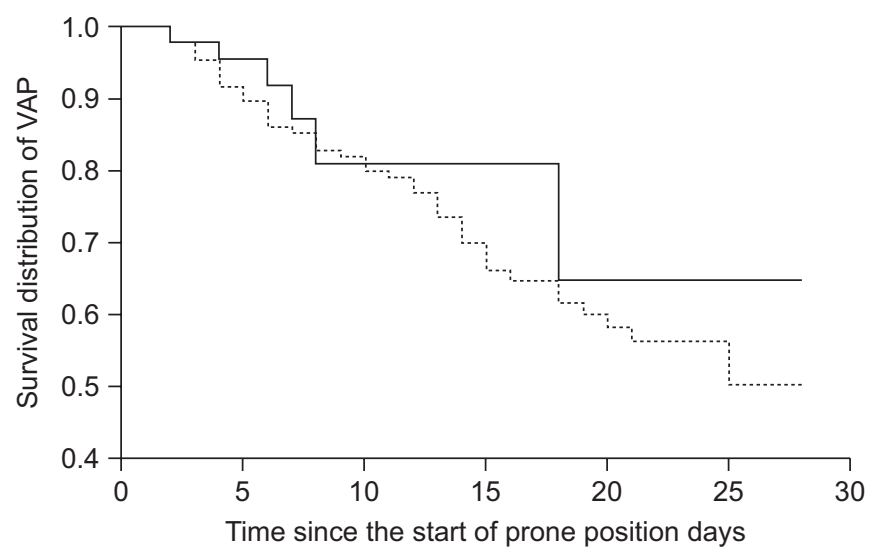

FIGURE 3. Kaplan-Meier estimates of the occurrence over time of ventilatorassociated pneumonia (VAP) in the group kept in the supine position (- - and in the group treated with prone positioning (…....). HR 1.64, 95\% Cl 0.70-3.84; $p=0.25$. 


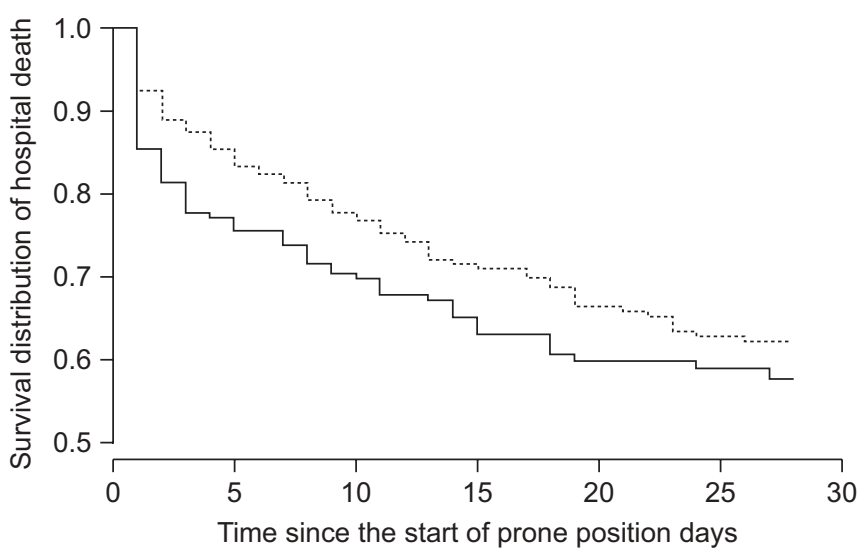

FIGURE 4. Kaplan-Meier estimates of 28-day hospital survival in the group kept in the supine position (- ${ }_{-}$and in the group treated with prone positioning $(\cdots \cdots \cdots)$. HR 0.56, 95\% Cl 0.39-0.79; $p=0.001$.

subgroup was defined by $\mathrm{Pa}_{1} \mathrm{O}_{2} / \mathrm{FI}_{1} \mathrm{O}_{2} \leqslant 88 \mathrm{mmHg}$, SAPS II $>49$, and tidal volume of $12 \mathrm{~mL} \cdot \mathrm{kg}^{-1}$. In our study, PP for $>2$ days was associated with significantly lower hospital mortality in patients with SAPS II $>50$ on the first day of PP. There was also a trend toward a decreased mortality in with $\mathrm{Pa}, \mathrm{O}_{2} / \mathrm{FI}, \mathrm{O}_{2}$ $<120 \mathrm{mmHg}$ (tables 5 and 6) corresponding to the quartile of patients with the lowest values in the initial study group (table 4). We did not study tidal volume because high volumes such as those reported by GATTINONI et al. [15] have not been used in our ICUs for over 10 yrs. Altogether, these data suggest that PP may be helpful in patients whose acute illness is very severe. Furthermore, they are consistent with a recently published meta-analysis showing that beyond the increase of $\mathrm{Pa}_{1} \mathrm{O}_{2} / \mathrm{FI}, \mathrm{O}_{2} \mathrm{PP}$ may improve survival in patients with greater severity of the acute illness [44] through other mechanisms. Furthermore, the fact that PP decreased mortality in this group may also suggest that we should use it for a longer period of time independently on the effect of its beneficial effect on gas exchange.

Our study has several limitations. The presence or absence of radiographic pulmonary infiltrates was not specifically recorded in the database. However, we performed a survey of all 12 participating centres to ensure that they all use this specific classic characteristic of ALI/ARDS. There is no consensus regarding the criteria for using PP or the optimal duration of PP. In addition, a possible centre effect was taken into account by including the centre in the propensity score.

In conclusion, our prospective multicentre cohort study suggests that the use of PP is not superior to SP to prevent VAP. However, PP may improve survival in longer PP use and in the sickest patients.

\section{STATEMENT OF INTEREST}

Statements of interest for A.T. Dinh-Xuan and E. Azoulay can be found at www.erj.ersjournals.com $/ \mathrm{misc} /$ statements.dtl

\section{ACKNOWLEDGEMENTS}

The authors' affiliations are as follows. R. Mounier: Assistance Publique-Hôpitaux de Paris, Louis Mourier Hospital, Medical ICU, Colombes, France. C. Adrie and A.T. Dinh-Xuan: Assistance PubliqueHôpitaux de Paris, Cochin hospital, University of René Descartes, Physiology Dept, Paris, France. A. Français: INSERM U823, Albert Bonniot Research Center, team 11, Outcome of cancers and critical illnesses, La Tronche, France. M. Garrouste-Orgeas: Medical-Surgical ICU, Saint Joseph Hospital, Paris, France. C. Cheval: Medical-Surgical ICU, Hyères Hospital, Hyères, France. B. Allaouchiche: Surgical ICU, Edouard Heriot Hospital, Lyon, France. S. Jamali: Medical-Surgical ICU, Dourdan Hospital, Dourdan, France. D. Goldgran-Toledano: Medical-Surgical ICU, Gonesse Hospital, Gonesse, France. Y. Cohen: Medical-Surgical ICU, Avicenne Teaching Hospital, Bobigny, France. E. Azoulay: Medical ICU, Saint-Louis Teaching Hospital, Paris, France. J-F. Timsit: INSERM U823, Albert Bonniot Research Center, team 11, Outcome of cancers and critical illnesses, La Tronche and Medical ICU, Albert Michallon Teaching Hospital, Grenoble, France. J-D. Ricard: Assistance Publique-Hôpitaux de Paris, Louis Mourier Hospital, Medical ICU, Colombes and INSERM U722, UFR of Medicine, University of Bichat, Paris, France.

The members of the OUTCOMEREA Study Group are as follows. Scientific committee: J-F. Timsit (Hôpital Albert Michallon and INSERM U823, Grenoble, France); P. Moine (Surgical ICU, Dept of Anesthesiology, University of Colorado, Denver, CO, USA); A. de Lassence (ICU, Hôpital Louis Mourier, Colombes, France); E. Azoulay (Medical ICU, Hôpital Saint Louis, Paris, France); Y. Cohen (ICU, Hôpital Avicenne, Bobigny, France); M. Garrouste-Orgeas (ICU Hôpital Saint-Joseph, Paris, France); L. Soufir (ICU, Hôpital SaintJoseph, Paris, France); J-R. Zahar (Dept of Microbiology, Hôpital Necker, Paris, France); C. Adrie (Dept of Physiology, Hôpital Cochin, France); A. Benali (Microbiology and Infectious Diseases, Hôpital

TABLE 5 Post hoc analyses of the effects of prone positioning (PP) on the occurrence of ventilator-associated pneumonia (VAP)

\begin{tabular}{|c|c|c|c|c|c|c|}
\hline \multirow[t]{2}{*}{ Population } & \multicolumn{2}{|c|}{ Sample size } & \multicolumn{4}{|c|}{ VAP } \\
\hline & Supine & Prone & Supine & Prone & HR (95\% Cl) & p-value \\
\hline All & 199 & 199 & $8(4)$ & $49(24.6)$ & $1.64(0.70-3.84)$ & 0.25 \\
\hline Single day of PP & 109 & 109 & $7(6.4)$ & $12(11)$ & $1.11(0.39-3.10)$ & 0.85 \\
\hline$\geqslant 2$ days of PP (time-dependent covariate) & 90 & 90 & $1(1.1)$ & $37(41.1)$ & $0.72(0.32-1.65)$ & 0.44 \\
\hline Only patients with $\mathrm{Pa}, \mathrm{O}_{2} / \mathrm{Fl}_{1} \mathrm{O}_{2}$ ratio $<\mathbf{2 0 0}$ at admission & 153 & 153 & $7(4.6)$ & $40(26.1)$ & $1.03(0.42-2.56)$ & 0.94 \\
\hline
\end{tabular}

Data are presented as $\mathrm{n}$ or $\mathrm{n}(\%)$, unless otherwise stated. $\mathrm{Pa}, \mathrm{O}_{2} / \mathrm{FI}, \mathrm{O}_{2}$ : arterial oxygen tension/inspiratory oxygen fraction ratio; SAPS II: Simplified Acute Physiology Score. The marginal Cox model was used to compute the hazard ratio (HR) adjusted on imbalances between groups and risk factors for events. 
TABLE 6 Post hoc analyses of the effects of prone positioning (PP) on the occurrence of death

\begin{tabular}{|c|c|c|c|c|c|c|}
\hline \multirow[t]{2}{*}{ Population } & \multicolumn{2}{|c|}{ Sample size } & \multicolumn{4}{|c|}{ Death } \\
\hline & Supine & Prone & Supine & Prone & HR $(95 \% \mathrm{Cl})$ & p-value \\
\hline All & 199 & 199 & $74(37.2)$ & $73(36.7)$ & $0.56(0.39-0.79)$ & 0.001 \\
\hline Single day of PP & 109 & 109 & $31(33)$ & $46(42.2)$ & $0.83(0.51-1.35)$ & 0.45 \\
\hline$\geqslant 2$ days of PP (time-dependent covariate) & 90 & 90 & $38(42.2)$ & $27(30)$ & $0.30(0.12-0.74)$ & 0.009 \\
\hline Only patients with $\mathrm{Pa}, \mathrm{O}_{2} / \mathrm{Fl}_{1}, \mathrm{O}_{2}$ ratio $<200$ at admission & 153 & 153 & $53(34.6)$ & $61(39.9)$ & $0.90(0.61-1.32)$ & 0.58 \\
\hline
\end{tabular}

Saint-Joseph, Paris France); C. Clec'h (ICU, Hôpital Avicenne, Bobigny, France); and J. Carlet (ICU, Hôpital Saint-Joseph, Paris, France).

Biostatistical and informatics expertise (all France): J-F. Timsit; S. Chevret (Medical Computer Sciences and Biostatistics Dept, Hôpital Saint-Louis, Paris); C. Alberti (Medical Computer Sciences and Biostatistics Dept, Robert Debré, Paris); A. Francais (Epidemiology of Cancer and Severe Illnesses, INSERM U823, Grenoble); M. Tafflet (Outcomerea, France); F. Lecorre (Supelec, Gif-sur-Yvette); and D. Nakache (Conservatoire National des Arts et Métiers, Paris).

Investigators of the OUTCOMEREA database (all France): C. Adrie; B. Allaouchiche (surgical ICU, Hôpital Edouard Herriot, Lyon); C. Bornstain (ICU, Hôpital de Montfermeil); A. Boyer (ICU, Hôpital Pellegrin, Bordeaux); A. Caubel (ICU, Hôpital Saint-Joseph, Paris); A.T. Dinh-Xuan (Dept of Physiology, Hôpital Cochin, Paris); C. Cheval (SICU, Hôpital Saint-Joseph, Paris); M-A. Costa de Beauregard (Nephrology, Hôpital Tenon, Paris); J-P. Colin (ICU, Hôpital de Dourdan, Dourdan); A-S. Dumenil (Hôpital Antoine Béclère, Clamart); A. Descorps-Declere (Hôpital Antoine Béclère, Clamart); J-P. Fosse (ICU, Hôpital Avicenne, Bobigny); S. Jamali (ICU, Hôpital de Dourdan, Dourdan); C. Laplace (ICU, Hôpital Kremlin-Bicêtre, Bicêtre); T. Lazard (ICU, Hôpital de la Croix Saint-Simon, Paris); E. Le Miere (ICU, Hôpital Louis Mourier, Colombes); L. Montesino (ICU, Hôpital Bichat, Paris); B. Mourvillier (ICU, Hôpital Bichat, Paris); B. Misset (ICU, Hôpital Saint-Joseph, Paris); D. Moreau (ICU, Hôpital Saint-Louis, Paris); R. Mounier (ICU, Hôpital Louis Mourier, Colombes); E. Pigné (ICU, Hôpital Louis Mourier, Colombes); C. Schwebel (University hospital A Michallon, Grenoble); J-F. Timsit; G. Troché (Hôpital Antoine Béclère, Clamart); M. Thuong (Agence de Biomédicine, Saint Denis); D. Golgran-Toledano ( $\mathrm{CH}$ Gonesse, Gonesse); E. Vantalon (SICU, Hôpital Saint-Joseph, Paris); and F. Vincent (ICU, Hôpital Avicenne, Bobigny).

Clinical research assistants: C. Tournegros, S. Calvino and L. Ferrand (Hôpital Albert Michallon, Grenoble, France); and S. Bekhouche (Hôpital Saint Louis, Paris, France).

We are indebted to A. Wolfe for manuscript editing. In memoriam of A. de Lassence, one of the founding members of the OUTCOMEREA group and a friend. He remains always in our minds and in our hearts.

\section{REFERENCES}

1 Adrie C, Alberti C, Chaix-Couturier C, et al. Epidemiology and economic evaluation of severe sepsis in France: age, severity, infection site, and place of acquisition (community, hospital, or intensive care unit) as determinants of workload and cost. J Crit Care 2005; 20: 46-58.
2 Chastre J, Fagon JY. Ventilator-associated pneumonia. Am J Respir Crit Care Med 2002; 165: 867-903.

3 Dreyfuss D, Ricard JD. Acute lung injury and bacterial infection. Clin Chest Med 2005; 26: 105-112.

4 Chastre J, Trouillet JL, Vuagnat A, et al. Nosocomial pneumonia in patients with acute respiratory distress syndrome. Am J Respir Crit Care Med 1998; 157: 1165-1172.

5 Delclaux C, Roupie E, Blot F, et al. Lower respiratory tract colonization and infection during severe acute respiratory distress syndrome: incidence and diagnosis. Am J Respir Crit Care Med 1997; 156: 1092-1098.

6 Markowicz P, Wolff M, Djedaini K, et al. Multicenter prospective study of ventilator-associated pneumonia during acute respiratory distress syndrome. Incidence, prognosis, and risk factors. ARDS Study Group. Am J Respir Crit Care Med 2000; 161: 1942-1948.

7 Pelosi P, Brazzi L, Gattinoni L. Prone position in acute respiratory distress syndrome. Eur Respir J 2002; 20: 1017-1028.

8 Esteban A, Anzueto A, Alia I, et al. How is mechanical ventilation employed in the intensive care unit? An international utilization review. Am J Respir Crit Care Med 2000; 161: 1450-1458.

9 Esteban A, Anzueto A, Frutos F, et al. Characteristics and outcomes in adult patients receiving mechanical ventilation: a 28-day international study. JAMA 2002; 287: 345-355.

10 Broccard A, Shapiro RS, Schmitz LL, et al. Prone positioning attenuates and redistributes ventilator-induced lung injury in dogs. Crit Care Med 2000; 28: 295-303.

11 Hess DR. Patient positioning and ventilator-associated pneumonia. Respir Care 2005; 50: 892-898.

12 Mackenzie CF. Anatomy, physiology, and pathology of the prone position and postural drainage. Crit Care Med 2001; 29: 1084-1085.

13 Guerin C, Badet M, Rosselli S, et al. Effects of prone position on alveolar recruitment and oxygenation in acute lung injury. Intensive Care Med 1999; 25: 1222-1230.

14 van Kaam AH, Lachmann RA, Herting E, et al. Reducing atelectasis attenuates bacterial growth and translocation in experimental pneumonia. Am J Respir Crit Care Med 2004; 169: 1046-1053.

15 Gattinoni L, Tognoni G, Pesenti A, et al. Effect of prone positioning on the survival of patients with acute respiratory failure. $N$ Engl $J$ Med 2001; 345: 568-573.

16 Mancebo J, Fernandez R, Blanch L, et al. A multicenter trial of prolonged prone ventilation in severe acute respiratory distress syndrome. Am J Respir Crit Care Med 2006; 173: 1233-1239.

17 Guerin C, Gaillard S, Lemasson S, et al. Effects of systematic prone positioning in hypoxemic acute respiratory failure: a randomized controlled trial. JAMA 2004; 292: 2379-2387.

18 Bornstain C, Azoulay E, De Lassence A, et al. Sedation, sucralfate, and antibiotic use are potential means for protection against 
early-onset ventilator-associated pneumonia. Clin Infect Dis 2004; 38: 1401-1408.

19 Clec'h C, Schwebel C, Francais A, et al. Does catheter-associated urinary tract infection increase mortality in critically ill patients? Infect Control Hosp Epidemiol 2007; 28: 1367-1373.

20 de Lassence A, Timsit JF, Tafflet M, et al. Pneumothorax in the intensive care unit: incidence, risk factors, and outcome. Anesthesiology 2006; 104: 5-13.

21 Garrouste-Orgeas M, Timsit JF, Tafflet M, et al. Excess risk of death from intensive care unit-acquired nosocomial bloodstream infections: a reappraisal. Clin Infect Dis 2006; 42: 1118-1126.

22 McCabe WR, Jackson GG. Gram-negative bacteremia, I: etiology and ecology. Arch Intern Med 1962; 110: 847-853.

23 Le Gall JR, Lemeshow S, Saulnier F. A new Simplified Acute Physiology Score (SAPS II) based on a European/North American multicenter study. JAMA 1993; 270: 2957-2963.

24 Vincent JL, Moreno R, Takala J, et al. The SOFA (Sepsis-related Organ Failure Assessment) score to describe organ dysfunction/ failure. On behalf of the Working Group on Sepsis-Related Problems of the European Society of Intensive Care Medicine. Intensive Care Med 1996; 22: 707-710.

25 Knaus WA, Draper EA, Wagner DP, et al. APACHE II: a severity of disease classification system. Crit Care Med 1985; 13: 818-829.

26 Misset B, Nakache D, Vesin A, et al. Reliability of diagnostic coding in intensive care patients. Crit Care 2008; 12: R95.

27 Adrie C, Azoulay E, Francais A, et al. Influence of gender on the outcome of severe sepsis: a reappraisal. Chest 2007; 132: 1786-1793.

28 Tafflet M. Finding matched controls for a case-control study using your own criteria: SAS Macro programming. Available from: www.outcomerea.org/ehtm/matchmacro.pdf.

29 Lee E, WeiL L, Amato D. Cox-type regression analysis for large number of small groups of correlated failure time observations. In: Klein J, Goel P, eds. Survival Analysis: State of the Art. Kluwer, Dordrecht, 1992; pp 237-247.

30 Douglas WW, Rehder K, Beynen FM, et al. Improved oxygenation in patients with acute respiratory failure: the prone position. Am Rev Respir Dis 1977; 115: 559-566.

31 Page B, Vieillard-Baron A, Beauchet A, et al. Low stretch ventilation strategy in acute respiratory distress syndrome: eight years of clinical experience in a single center. Crit Care Med 2003; 31: 765-769.
32 Galiatsou E, Kostanti E, Svarna E, et al. Prone position augments recruitment and prevents alveolar overinflation in acute lung injury. Am J Respir Crit Care Med 2006; 174: 187-197.

33 Beuret $\mathrm{P}$, Carton MJ, Nourdine K, et al. Prone position as prevention of lung injury in comatose patients: a prospective, randomized, controlled study. Intensive Care Med 2002; 28: 564-569.

34 Drakulovic MB, Torres A, Bauer TT, et al. Supine body position as a risk factor for nosocomial pneumonia in mechanically ventilated patients: a randomised trial. Lancet 1999; 354: 1851-1858.

35 Reignier J, Thenoz-Jost N, Fiancette M, et al. Early enteral nutrition in mechanically ventilated patients in the prone position. Crit Care Med 2004; 32: 94-99.

36 Mentec $\mathrm{H}$, Dupont $\mathrm{H}$, Bocchetti $\mathrm{M}$, et al. Upper digestive intolerance during enteral nutrition in critically ill patients: frequency, risk factors, and complications. Crit Care Med 2001 29: 1955-1961.

37 Schortgen F, Bouadma L, Joly-Guillou ML, et al. Infectious and inflammatory dissemination are affected by ventilation strategy in rats with unilateral pneumonia. Intensive Care Med 2004; 30: 693-701.

38 Johanson WG, Pierce AK, Sanford JP. Changing pharyngeal bacterial flora of hospitalized patients. Emergence of gramnegative bacilli. $N$ Engl J Med 1969; 281: 1137-1140.

39 Johanson WG Jr, Pierce AK, Sanford JP, et al. Nosocomial respiratory infections with gram-negative bacilli. The significance of colonization of the respiratory tract. Ann Intern Med 1972; 77: 701-706

40 Curley MAQ, Hibberd PL, Fineman LD, et al. Effect of prone positioning on clinical outcomes in children with acute lung injury: a randomized controlled trial. JAMA 2005; 294: 229-237.

41 Pelosi P, Tubiolo D, Mascheroni D, et al. Effects of the prone position on respiratory mechanics and gas exchange during acute lung injury. Am J Respir Crit Care Med 1998; 157: 387-393.

42 Voggenreiter G, Aufmkolk M, Stiletto RJ, et al. Prone positioning improves oxygenation in post-traumatic lung injury - a prospective randomized trial. J Trauma 2005; 59: 333-341.

43 Ware LB, Matthay MA. The acute respiratory distress syndrome. N Engl J Med 2000; 342: 1334-1349.

44 Alsaghir AH, Martin CM. Effect of prone positioning in patients with acute respiratory distress syndrome: a meta-analysis. Crit Care Med 2008; 36: 603-609. 